\title{
Using the PARAGON Framework to Establish an Accurate, Consistent, and Cohesive Long-Term Aerosol Record
}

\author{
by David J. Diner, Robert T. Menzies, Ralph A. Kahn, Theodore L. Anderson, \\ Jens Bösenberg, Robert J. Charlson, Brent N. Holben, Chris A. Hostetler, \\ Mark A. Miller, John A. Ogren, Graeme L. Stephens, Omar Torres, \\ Bruce A. Wielicki, Philip J. Rasch, Larry D. Travis, and William D. Collins
}

\begin{abstract}
Advances in measurement capabilities and technologies will make possible high-quality, validated, and systematic aerosol observations.
\end{abstract}

A $s$ discussed in companion papers (Kahn et al. 2004b; Ackerman et al. 2004), a comprehensive aerosol observing system must incorporate and integrate surface, airborne, and satellite-based data. Consistency over time of the measurement record based on these diverse sources is essential if we are to understand the causes of climate variability. Consequently, sensor calibration, data and algorithm validation, and continuous quality control are critical.
Maintaining an aerosol observing system over the long term also demands a sustained investment of resources, and studies are needed to determine the most cost-effective means of obtaining and validating the required measurements and filling the observational gaps. To achieve a balanced program, these studies should consider how satellite, surface-based, and in situ data sources will be used together. This holistic viewpoint is a key ingredient of the Progressive Aero- affiliations: Diner, Menzies, ANd KaHN-Jet Propulsion Laboratory, California Institute of Technology, Pasadena, California; ANDERSON AND CHARLSON-University of Washington, Seattle, Washington; BÖSENBERG-Max-Planck-Institut für Meteorologie, Hamburg, Germany; HoLBEN-NASA Goddard Space Flight Center, Greenbelt, Maryland; HostetLeR AND WIELICKI—NASA Langley Research Center, Hampton, Virginia; MILleR—Brookhaven National Laboratory, Upton, New York; OGREN-NOAA Climate Monitoring and Diagnostics Laboratory, Boulder, Colorado; STEPHENSColorado State University, Fort Collins, Colorado; TORRES-
University of Maryland, Baltimore County, Baltimore, Maryland; RASCH AND Collins-National Center for Atmospheric Research, Boulder, Colorado; TRAVIs-NASA Goddard Institute for Space Studies, New York, New York CORRESPONDING AUTHOR: David J. Diner, JPL Mail Stop 169 237, 4800 Oak Grove Drive, Pasadena, CA 91109

E-mail: djd@jord.jpl.nasa.gov DOI:10.II75/BAMS-85-10-I535

In final form 28 July 2004

C2004 American Meteorological Society 
sol Retrieval and Assimilation Global Observing Network (PARAGON) concept (Diner et al. 2004a). PARAGON provides a vehicle for organizing and exchanging data acquired from both existing and newly developed sensors, and offers a systematic way of evaluating the impact of new measurements on our understanding of aerosols.

CALIBRATION AND VALIDATION. Calibration is critical for any climate observing system, especially in light of the potential for natural variability to obscure secular climate change. A multiagency workshop (Ohring et al. 2004) considered the stability and absolute accuracy requirements for satellitederived aerosol parameters, for example, accuracy of \pm 0.01 in aerosol optical depth (AOD) and \pm 0.03 in single scattering albedo (SSA). Given the high accuracies required for isolating climate signatures (in particular, anthropogenic influences), careful attention to measurement calibration and independent validation must be maintained. Because aerosol amounts and types are highly variable, spatial and temporal sampling requirements also must be looked at carefully to meet global change needs. For most measurements, Ohring et al. (2004) noted that instrument stability is more critical than absolute accuracy, though they concluded that improvements in both are required broadly across climate instruments.

Rigorous analysis of data products to achieve the necessary accuracy, stability, and traceability should be encouraged. As noted in Seinfeld et al. (2004), the uncertainties and inconsistencies associated with current measurement systems, in particular, satellite instruments, are too large to meet the required climate accuracies. Modern laboratory standards developed by the National Institute for Standards and Technology (NIST) achieve $0.1 \%$ radiometric uncertainty in the visible and near-infrared (Brown et al. 2000; Eppeldauer et al. 2000). Attaining performance anywhere near this level with remote sensing radiometers has proven to be elusive, especially for imaging systems where the best current absolute uncertainties are about 3\%.

Measurement uncertainties must be understood in great detail and continually advanced. For example, a recently completed analysis of calibration data for the Terra Multiangle Imaging SpectroRadiometer (MISR) led to an adjustment of the instrument's radiometric scale by $-3 \%$ in the red and $-1 \%$ in the near-infrared (Bruegge et al. 2004). These small adjustments translate into an average reduction of $\sim 0.02$ in the retrieved 558-nm aerosol optical depth over dark ocean sites (Kahn et al. 2004c). An additional
$3 \%-4 \%$ bias exists between the independently derived absolute radiometric scales of MISR and the Terra Moderate Resolution Imaging Spectroradiometer (MODIS) (Bruegge et al. 2004), and corresponds to an optical depth difference of $\sim 0.02$. Such studies emphasize the need for investment in research and technologies to improve sensor calibration and cross calibration. Unless we develop better ways to reduce calibration uncertainties and maintain accuracy and stability over long periods, these factors will continue to limit progress in understanding aerosol effects on climate.

Multiple approaches are needed to ensure robustness of climate inferences. Ohring et al. (2004) supplemented existing climate and satellite observing principles (NRC 1999; GCOS 2003) with a requirement for independent observations and independent analysis for each key climate parameter. The reasons for this requirement include the difficulty of achieving climate quality accuracy with most instruments, the scientific need to independently verify surprising climate change results, and the large economic and societal impacts of climate change policy decisions that are made as a result of scientific research.

For aerosols, this requirement suggests the need for both active and passive measurements, as well as for multiple analyses of each key dataset and, ultimately, for systematic methods of validation of parameters obtained by remote sensing. As sensors evolve and new technologies are developed, it is particularly important to ensure that inferred temporal trends in the environment and climate are not artifacts of a changing measurement system. This makes frequent, ongoing, and reliable validation critical. However, for many key parameters, satellite measurement approaches and systematic validation methodologies do not yet exist (see the sidebar, "The need for systematic validation of satellite data," for further details).

\section{MAINTENANCE AND AUGMENTATION OF SURFACE NETWORKS AND IN SITU MEASUREMENTS ALOFT. A network of refer-} ence stations, in combination with advanced spacebased sensors, can capture the major features of aerosol fields. Surface networks are relatively inexpensive compared to satellite instrumentation, but work needs to be done to maintain and improve them, including expansion into key areas. Unfortunately, long-term stable funding sources to maintain, upgrade, and operationalize many networks do not yet exist.

Site choices for surface stations are a trade-off between quality and quantity of retrievals on the one hand, and network cost and complexity (including 
operation and maintenance) on the other. Nonetheless, at least one station that is capable of comprehensive aerosol characterization should be installed in each region where important aerosol types occur. Denser surface networks may be needed where aerosol burden and variability are great, for example, in densely populated and industrialized areas such as the eastern United States, western Europe, and parts of Asia. Greater geographical coverage with in situ observations, including the use of airborne systems, would enhance our needed ability to routinely assess uncertainties of column-integrated microphysical parameters. Adequate meteorological instrumentation and high-quality regional trajectory and source models are also necessary for interpreting the data.

Surface and airborne networks have many current needs for systematic quality control, not just expansion. Given the diversity of data types, vantage points, measurement complexities, and potential spatiotemporal coverage issues, systematic analysis is needed to optimize network deployment. Establishment of uniform quality control is essential, implying a need for high-level organization. Experience with the Background Air Pollution Monitoring Network (BAPMoN) has shown that instruments, processing, calibration protocols, and data access must be standardized, and international networks must coordinate their efforts in order to provide unified products. Systematic quality control and data evaluation have been successfully demonstrated within the Aerosol Robotic Network (AERONET) (Holben et al. 1998, 2001) and the European Aerosol Research Lidar Network (EARLINET) (Bösenberg et al. 2002).

An ocean-based radiometer network. Although a wellcalibrated, over-ocean cloud and aerosol radiation network is feasible, oceans remain highly undersampled. The Shipboard Oceanographic and Atmospheric Radiation (SOAR) program (Reynolds et al. 2001) has addressed the difficulties in making opti-

\section{THE NEED FOR SYSTEMATIC VALIDATION OF SATELLLITE DATA}

Only in the case of AOD have surfacebased radiometer systems such as AERONET made possible quantitative, systematic, globally distributed validations of satellite retrievals. Remote sensing of other optical and microphysical properties is less mature, and the validation state of the art is similarly less well developed.

Retrieval and validation of SSA are especially challenging: an error of a few percent can make the difference between inferred tropospheric heating or cooling for a given surface albedo (e.g., Russell et al. 2002). One suggested method involves satellite observations at multiple angles within and outside of the sunglint pattern over oceans (Kaufman et al. 2002a). Because SSA is the integral of the aerosol phase function over all scattering angles, another possibility is to combine multiangle satellite views of forwardand backscattering with surface-based multiangle radiometer observations (Wang and Gordon 1993; Cattrall et al. 2003; Dubovik et al. 2003; Ackerman et al. 2004). A third approach is to take advantage of the interaction between near-ultraviolet molecular scattering and aerosol absorption, as demonstrated using TOMS measurements at 340 and $380 \mathrm{~nm}$ (Torres et al. 1998, 2002a). This method requires knowing the height of the absorbing aerosol layer (e.g., from a backscatter lidar), and particle models must be assumed to extrapolate to the rest of the solar spectrum. Another proposed method uses measurements within the oxygen A band (e.g., Labonnote and Stephens 2003). Techniques using advanced lidars are also being explored, and provide the benefit of vertical resolution.

Establishing the accuracies of these approaches is essential, though not necessarily simple. Field measurements obtained a difference of about 0.05 between the SSA inferred from column flux measurements and more direct approaches, but with uncertain statistical significance (Russell et al. 2002). Furthermore, the spectral dependence of absorption is large and variable for many pollution and biomass-burning particle types. Currently, field measurements of SSA spectral dependence, for example, with multiple particle soot absorption photometers (Bond et al. 1999), are rarely done, even for major campaigns (Russell et al. 2002; Kahn et al. 2004a).

Another critical but challenging parameter is aerosol anthropogenic fraction. Kaufman et al. (2002b) suggest that the submicron fraction can serve as a proxy for this quantity. Satellite data products (e.g., from MODIS and MISR) include fine-, medium-, and coarse-mode optical depth fractions, but their accuracies are not yet well understood and have not yet been systematically compared against independent data. Because anthropogenic origin must ultimately be assessed on a chemical basis (e.g., as by Ramanathan et al. 200I), in situ measurements of size-resolved aerosol chemical composition and reliable methods of source attribution are needed to explore the validity of the Kaufman et al. (2002b) hypothesis.

With regard to the task of distinguishing fine- and coarse-mode extinction, in situ methods are well established and highly accurate, and can be deployed in both ground-based (e.g., Delene and Ogren 2002) and airborne (e.g., Anderson et al. 2003b) sampling modes. A challenge is to obtain a statistically significant number of validation tests adequately collocated with remote sensors. "Environmental snapshots" can constrain the relationship between in situ measurements of individual air parcels and column measurements from radiometers and vertical profiles from lidars (Kahn et al. 2004a). 
cal depth measurements from mobile sea-going platforms (Miller et al. 2004). An expanded version of SOAR could transmit data to a central processing facility in near-real time, as is done with AERONET. The data quality control algorithms for a ship-based network have been developed as part of the National Aeronautics and Space Administration (NASA) and Department of Energy (DOE) programs (Fargion et al. 2001). Ocean-based measurements, along with coastal lidars, can be integrated with coastal measurements from AERONET and used with trajectory and chemical transport models (CTMs) to estimate aerosol properties downwind of continental source regions. Ironically, despite successful technology demonstrations, the development of a mature data processing system, and availability of ships traveling recurring routes of interest, long-term support to make such a system operational has not been established.

A more uniform lidar network. A global surface lidar network also does not exist. Rather, different groups operate regional networks using different techniques. Existing networks need to expand into undersampled regions, such as Southern Hemisphere biomass-burning locations, and upgrade to more homogeneous and advanced instruments. Furthermore, networks are most useful when aerosol properties can be obtained with uniform, specified quality from all stations. This is probably impossible with pure backscatter lidars because of calibration-related problems and the need for an assumed extinction-to-backscatter ratio profile under widely varying conditions. However, such lidars [e.g., the Micropulse Lidar Network (MPLNET); Welton et al. 2001] can reliably measure aerosol vertical distribution in regions where more complex systems are difficult to operate. With lidars having additional channels to detect molecular scattering (Raman or Rayleigh), even a network comprised of many varying systems can yield good results (Matthias et al. 2004; Böckmann et al. 2004).

In situ samplers aloft. Several enhancements in chemical sampling data are essential to provide the most value in evaluating and improving CTMs. Critical needs include aerosol chemical measurements that can attribute effects to specific sources and to connect satellite observations to CTMs. Such measurements are needed aloft, allowing for an assessment of how well point measurements at surface stations represent the column, as well as the surrounding region. Sizesegregated chemical measurements for coarse and fine aerosols, and sample times much shorter than the current 24-h standard, are needed, at least in some locations. A program of sustained airborne measurements is a key ingredient of an integrated observing system, which is particularly helpful to support process studies, validation, and demonstrations of coherency between model predictions and remote sensing observations. Vertical profiling from aircraft can provide information on aerosols that act as ice nucleian issue that is looming as an important, unconstrained problem (Penner et al. 2001).

The supersite imperative. Current supersites do not provide the full suite of complex, coordinated chemical and cloud condensation nuclei (CCN) measurements that are needed to link changes in aerosol properties to changes in cloud properties. Priority should be given to the establishment of a small network of supersites combining sunphotometers and lidars to retrieve microphysical column properties, preferably in combination with those supersites providing in situ measurements.

REMOTE SENSING ADVANCEMENTS. Providing an accurate description of aerosol distributions and microphysical properties, and using such information to improve and validate CTMs, are major components of PARAGON. Particular observational needs include methods for improving accuracies in aerosol column abundances and microphysical properties, and measuring aerosol-layer heights with good spatial and temporal coverage.

A major source of uncertainty in deriving columnintegrated aerosol properties passively from space is the intertwining of the effects of AOD, SSA, and phase function on scattered radiances (Mishchenko et al. 1995; Wang and Gordon 1994). Reflection from the surface is an added complication. Uncertainties in spectral AOD achieved from satellites need to be reduced by a factor of 2-3 to attain the level of accuracy required for climate studies (NACIP 2002). Even if the errors are random, temporal averaging (e.g., monthly) to reduce them is insufficient, given the short atmospheric residence times of aerosols.

Simultaneous multispectral, multiangular, and polarimetric satellite imaging could reduce instantaneous retrieval uncertainties because of the complementary sensitivities of these different techniques to particle characteristics. Combining such measurements with upward-looking retrievals when coincident data exist (Dubovik et al. 2003; Ackerman et al. 2004), and using CTMs to constrain aerosol type within satellite-based retrievals, could further improve retrieval accuracies. Validated CTMs can also cover regions where measurements are missing or 
highly uncertain (Yu et al. 2003; Ackerman et al. 2004).

Within an atmospheric column, the vertical distribution of aerosol absorption is required to calculate the atmospheric heating rate and its effect on atmospheric stability and radiative transfer. Lidars provide the most direct means of observing vertical profiles of aerosol backscattering and extinction, particularly advanced systems that are capable of separating these variables and characterizing aerosol microphysics. Although passive methods of constraining aerosol height are unlikely to provide the kind of detailed profiles achievable with lidars, they can provide wide spatial coverage much more readily. The potential of such methods to constrain CTMs should also be explored.

Column-integrated passive systems. Satellite imaging of aerosols is an important source of data that includes contextual information, spatial resolution sufficient to identify clouds, and frequent sampling above surface-based stations. The unique strengths of multispectral (ultraviolet through shortwave infrared), multiangle, and polarimetric observations are summarized in Kahn et al. (2004b). However, no existing or currently manifested satellite imager combines all of the salient attributes and accuracies of these techniques. Sensor fusion is likely to provide both economic advantages, as well as technical (e.g., accuracy, simultaneity, resolution, and coverage) improvements. For example, extending the spectral coverage of an advanced imager into the near-ultraviolet would make possible, at a higher spatial resolution, the approach developed for the Total Ozone Mapping Spectrometer (TOMS) by Torres et al. $(1998,2002 \mathrm{a})$ for identifying aerosol absorption.

The most difficult challenge for a unified instrument is polarimetric imaging at very high accuracy. Spectropolarimetry appears to be the most sensitive passive technique for obtaining a particle refractive index, which helps to constrain aerosol type. Studies with the airborne Research Scanning Polarimeter (RSP) suggest that this quantity can be retrieved for accumulation and coarse-mode aerosols using a combination of visible and shortwave infrared observations (Chowdhary et al. 2002). Because this technique inherently entails a relative measurement (degree of polarization), it can be self-calibrating. Combined with multiangle and multispectral intensity measurements, polarimetry has the potential to reduce uncertainties in retrieved optical properties compared to those derived from intensity data alone (Mishchenko and Travis 1997).
The RSP and the planned spaceborne Aerosol Polarimeter Sensor (APS) specify a degree of linear polarization uncertainty of $\sim 0.2 \%$ (Cairns et al. 1999), performance about a factor of $5-10$ better than the Polarization and Directional of the Earth's Reflectances (POLDER) instrument (Hagolle et al. 1999). However, the APS has large footprints ( 10 km), and its measurements are confined to single-pixel strips. Due to this coarse resolution and the earth's rotation, horizontal homogeneity over $\sim 10 \mathrm{~km}$ scales is required. An imager would circumvent this problem, but highaccuracy polarimetry must account for pixel-to-pixel gain variations and spatial misregistrations that can lead to false polarization signals. Solutions to this problem using high-speed polarization modulators, such as piezoelastic devices, liquid crystals, and rotating wave plates, are being explored for a number of imaging applications (Keller 2002). Piezoelastic modulators have achieved very high polarimetric precision for ground-based solar astronomy (Povel et al. 1994; Gandorfer and Povel 1997). Advances in focal plane technology are required for the shortwave infrared (Keller 2003). A multiangle imaging concept capable of near-ultraviolet to shortwave infrared spectral coverage, with high-accuracy polarimetric imaging in selected bands, is being developed for aerosol remote sensing (Diner et al. 2004b).

Height-resolving active systems. The most feasible wavelengths for active aerosol-height profiling are dictated by lidar technology, and commonly include the 1064-, 532-, and 355- $\mathrm{nm}$ wavelengths available from a neodymium: yttrium aluminum garnet (Nd:YAG) laser. Profile retrievals depend upon assumptions about the aerosol complex refractive index, though the sensitivity to error depends on the lidar method. Fortunately, the complex refractive indices for the most influential aerosol chemical composition types vary slowly throughout the visible and near-infrared. Particle shape complicates the interpretation of scattering data obtained at the shorter lidar wavelengths, particularly when particles are of a size nearly equal to or larger than the wavelength. However, lidars able to measure the orthogonal polarization components of the backscattered signals can, in principle, discern particle nonsphericity.

Because the elastic backscatter lidar signal derives from both aerosols and atmospheric molecules, retrieval of aerosol properties from this measurement alone requires dealing with a fundamental ambiguity because two aerosol variables (the backscatter and extinction coefficients) are present in a single lidar equation. The conventional solution is to prescribe 
a value for the extinction-to-backscatter ratio $S_{a}$, assume a boundary value for the extinction coefficient at a reference altitude, and then iterate, following the recipe of Klett $(1981,1985)$. Due to the wide diversity of aerosol types found in the troposphere, the range of values of $S$ deduced from observations and models is very wide, extending from about 10 to 100 sr. Much effort has been expended in attempts to bound the range of $S_{a}$ values for specific aerosol types (e.g., mineral dust, sea salt, sulfate, composite pollution) and to develop an $S_{a}$ "climatology." The natural variability of tropospheric aerosol, however, makes this approach problematic in many situations as a method for producing quantitative aerosol extinction profiles.

The High Spectral Resolution Lidar (HSRL) technique (Shipley et al. 1983; Sroga et al. 1983; She et al. 1992; Hair et al. 2001) potentially offers a more robust solution because of its ability to separate the effects of backscatter and extinction. Another method uses both elastic and Raman backscatter signals, the latter deriving from atmospheric nitrogen molecules (Ansmann et al. 1990). Both of these technologies are capable of retrieving vertical profiles of aerosol microphysical properties (see the sidebar, "Advanced lidar profiling techniques").
Height-sensitive passive systems. Achieving lidar observations with spatially continuous global coverage over time scales consistent with aerosol variability is unlikely. Hence, the observing improvements outlined above will still leave gaps. Obtaining aerosol vertical distributions from CTMs, validated at the locations where lidars operate, is one conceivable approach toward filling the gaps. The accuracy of CTM aerosol vertical profiles is closely related to the quality of the aerosol-source characterization in both location and strength. For example, model-calculated aerosol-layer heights using the Global Ozone Chemistry Aerosol Radiation and Transport (GOCART) model (Chin et al. 2002) yield reasonable TOMSAERONET comparisons of AOD for desert dust aerosols, for which GOCART has a reliable way of determining the aerosol sources. However, because identifying biomass-burning source areas is difficult, and information on the injection height of the smoke aerosols is lacking, the use of model calculations of aerosol vertical distribution as input to the TOMS retrieval algorithm does not produce satisfactory results for carbonaceous aerosols. Consequently, height information from passive instruments will also improve global coverage. There are several approaches for obtaining such data:
HSRL relies on the fact that aerosol backscatter is spectrally narrow compared with molecular backscatter-the latter being Doppler broadened due to the relatively large Maxwellian velocity distribution of the molecular scatterers. The technique employs a spectrally narrow laser transmitter and optical elements in the receiver to separate the molecular and aerosol backscatter signals. In the most common implementation, an atomic vapor filter is used in one optical channel to absorb the aerosol component of the backscatter, leaving only the Doppler-broadened wings of the molecular backscatter. The resulting profile is still affected by aerosol extinction. The other channel measures total backscatter. With these two sources of information, a closed-form solution for the extinction profile is possible without reliance on a priori knowledge of the extinction-tobackscatter ratio $S_{a}$. Approaches employing Fabry-Perot and MachZehnder interferometers have also been studied (e.g., Bruneau and Pelon 2003). A key advantage of the HSRL technique is that, with independent measurements of backscatter and extinction, the vertical profile of $S_{a}$ is obtained, making it possible to distinguish layers of different aerosol type (e.g., biomass smoke over continental aerosol). HSRL systems can be designed to be internally calibrated, resulting in accuracies far higher than any practical backscatter lidar. Moreover, there appears to be a credible roadmap toward deployment in Earth orbit.

As with HSRL, the Raman lidar technique obtains two independent signals that allow closed-form solutions for the two aerosol variables. In particular, the range-gated Raman backscatter signal from molecular $\mathrm{N}_{2}$ is affected only by aerosol extinction. This method has been used with increasing sophistication to demonstrate robust retrievals of microphysical parameters (effective radius, complex index of refraction, and SSA) along with the backscatter and extinction profiles. Althausen et al. (2000), Müller et al. (1999a,b, 2000a,b, 200I), and Veselovskii et al. (2002) have demonstrated this capability using multiwavelength elastic/Raman backscatter lidar systems. Microphysical parameter retrievals are also possible using multiwavelength HSRL data. Unlike HSRL, however, the Raman lidar approach is not feasible in earth orbit due to the relatively weak Raman scattering cross sections. This is a fundamental physical limitation, not a matter of technology availability. Nevertheless, this method is very effective for ground-based measurements and is widely viewed as the best method for implementation of a ground-based aerosol lidar network. 
- Under certain conditions, aerosol-height information can be obtained stereoscopically through pattern matching, most often near source regions, where distinct plume features are observed. Stereoscopy typically retrieves the altitude of the top of the plume. Automated patternmatching algorithms for MISR (Moroney et al. 2002; Muller et al. 2002; Zong et al. 2002) have height accuracies of a few hundred meters for low clouds (Naud et al. 2004). Plume-top altitudes for smoke, dust, and volcanic emissions are also routinely retrieved (see Fig. 1).

- Another potential approach is to use near-ultraviolet observations in at least a dual-viewingangle configuration for the simultaneous retrieval of AOD, SSA, and height of the absorbing aerosol layer. Radiative transfer simulations suggest that simultaneous observations at two different scattering angles can retrieve

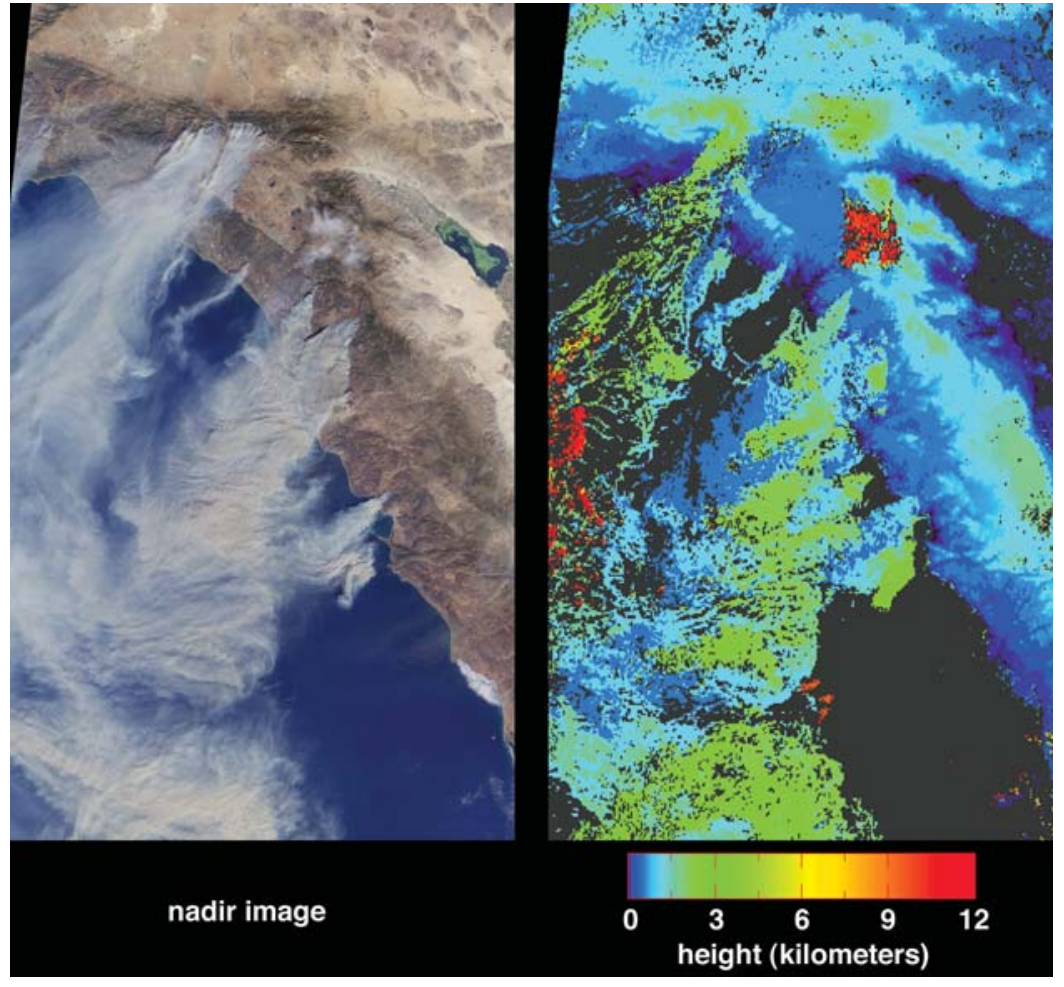

FIG. I. Stereoscopic retrieval of smoke plume-top elevations from MISR over southern California on 26 Oct 2003 during the fall 2003 outbreak of devastating fires: (left) natural color nadir image, (right) retrieved height field. The stereo matching successfully retrieves the heights of the plume tops, and differentiates smoke from high-altitude cirrus. these three parameters (Fig. 2).

- A third candidate method uses a portion of the solar spectrum that contains an absorption band associated with a gas of known concentration and, thus, known distribution. Both theory (e.g., Stephens and Heidinger 2000) and observations (O'Brien et al. 1998) indicate that in using the known absorption properties of a well-mixed gas, like molecular oxygen, it is possible to separate the contribution from scattering by aerosols from reflections by the underlying surface. As such, it be-

FIG. 2. Theoretical retrieval of AOD, SSA, and aerosol height using simulated dual-angle UV observations. The aerosol model used in this simulation has a bimodal particle size distribution with effective radii of the fine and coarse modes of 0.05 and $0.67 \mu \mathrm{m}$, respectively. (top) Retrieved AOD and SSA for three assumed values of the aerosol-layer height $(1.5,3.0$, and $6.0 \mathrm{~km})$ at two different viewing configurations corresponding to scattering angles of $150^{\circ}$ (red line) and $175^{\circ}$ (blue line). The two lines intersect at the actual values of AOD, SSA, and aerosol-layer height. (bottom) Values of the aerosol scattering phase function at the two viewing configurations used in the retrieval.

comes possible to extract information on aerosollayer height provided that measurements are of sufficient spectral resolution, are of an adequate signal-to-noise ratio (SNR), and are conducted in spectral bands that contain sufficiently strong ab-
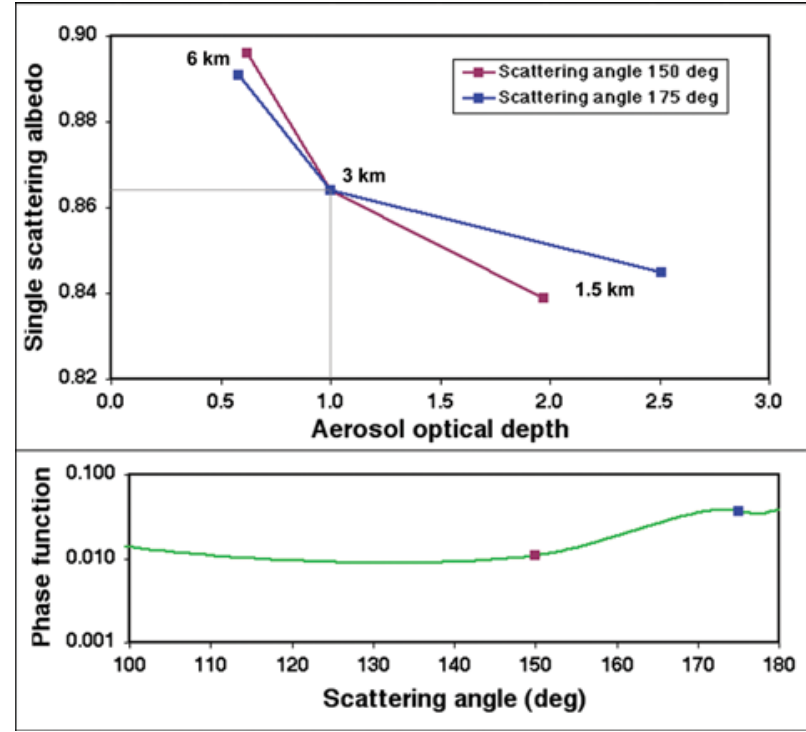
sorption lines. The potential value of highly resolved spectral measurements using an $\mathrm{O}_{2} \mathrm{~A}$-band spectrometer is shown in Fig. 3.

SATELLITE MISSION DESIGN. Assembling the measurement components of the PARAGON global observing network in a sustainable, effective way requires planning in advance for how the various pieces will work together. In contrast to the "business as usual" approach, this systems view considers each instrument as one component of an integrated "virtual" sensor, and plans explicitly for how the various elements are to be designed and situated. Accomplishing this will require a level of coordination that currently does not exist.

Orbit selection is a good example of the kind of holistic approach needed to develop satellite missions that complement surface-based or other satellite in-
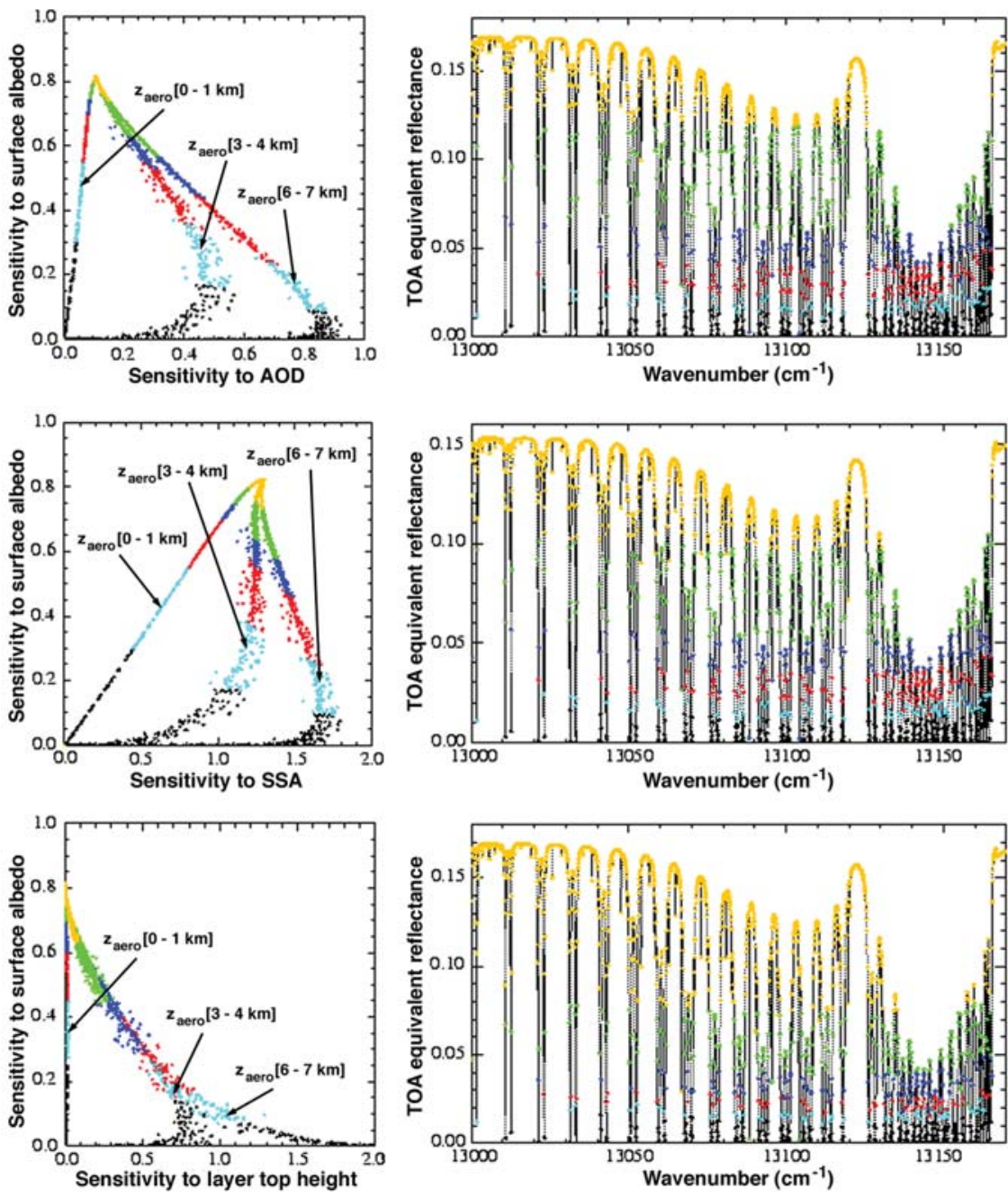

FIG. 3. Simulated sensitivities of an oxygen A-band spectrometer to (top) AOD, (middle) SSA, and (bottom) aerosol-layer height (adapted from Labonnote and Stephens 2003) for aerosol layers at three altitude ranges $\left(z_{\text {aero }}=1-2,3-\right.$ 4, and 6-7 km). The portions of the spectrum corresponding to a given sensitivity are matched by the color code. The right-hand plot of each panel is a model-derived spectrum of TOA-reflected sunlight as it would be measured by a satellite $\mathrm{O}_{2}$ A-band spectrometer with a resolution of $\mathrm{I} \mathrm{cm}^{-1}$. Sensitivity studies show that this resolution, along with high SNR ( 400:I for light levels defined with respect to a surface of $5 \%$ albedo illuminated at a $60^{\circ}$ solar zenith angle) are required. The spectrum shown is for a case corresponding to an optically thin aerosol layer over a land surface with $20 \%$ albedo. The lefthand plots show the sensitivity of the spectral reflectance to surface albedo changes (ordinate) and changes in the quantity plotted on the abscissa. struments and can be usefully integrated with atmospheric models. Orbit directly impacts satellite instrument capabilities, including sampling frequency of given locations, global coverage time, and size and power requirements. For example, because even highly capable imagers cannot provide detailed descriptions of aerosol chemistry, their designs (i.e., coverage, resolution) should take into account how they will be used in conjunction with in situ instruments. In addition, because surfacebased lidars offer good temporal coverage, trade-offs in the placement and number of surface sites vis-à-vis space-based lidars need to be examined, taking into account what is realistically achievable from space.

An illustration of the interplay between instrument design, data synthesis, and orbit selection is provided by considering the requirements for an advanced multiangle imager. Multiangle spectroradiometric, polarimetric, and stereoscopic retrieval approaches work by examining the same area at many angles within a short enough time span such that the airmass location, density, and morphology have not evolved (i.e., from minutes to under an hour). This means that near-simul- 
taneous coverage in zenith angle and scattering angle is required at each observed location. Furthermore, because the atmospheric residence times of aerosol layers range from weeks in the upper troposphere to a few hours near the surface or in clouds, with a typical value between 3 and 6 days (Rasch et al. 2001), global coverage over a 3-4-day period is required so that the data from an imager will provide useful input to assimilation models. We studied orbit trade-offs affecting the ability to meet these objectives. We find that low earth orbits (LEOs; altitude $<1000 \mathrm{~km}$ ) or medium earth orbits (MEOs; altitude $>1000 \mathrm{~km}$ ) are most suitable, and that 3- or 4-day global coverage appears attainable with reasonable orbit choices. Details are provided in the appendix.

Orbit selection will also affect how well an advanced satellite imager and lidar will work in combination. Rapidity of global coverage for an imager improves at higher orbit altitudes, but practical challenges for both imagers and lidars also increase. Because the power requirements of a lidar increase as the square of the range to the target, a space-based lidar system can be built much more economically if it is flown at lower altitude. This is particularly significant for HSRL technologies, which require relatively high backscattered signals in order to effectively derive independent backscatter and extinction profiles. An earth-orbiting HSRL instrument would likely require an energy-aperture product 5-10 times as large as the Cloud-Aerosol Lidar and Infrared Pathfinder Satellite Observations (CALIPSO) backscatter system (Winker et al. 2002; Poole et al. 2003), which will fly in the satellite "A train." Improving the achievable spatial coverage by scanning places additional demands on the lidar power requirements, although profile averaging can be used to improve sensitivity. In the long term, systematic aerosol observing missions can learn from the Terra and the A-train satellites and incorporate the next-generation passive and active remote sensing systems. The appendix describes potential orbit scenarios that illuminate some of the mission design trade-offs for a passive-active sensor combination.

CONCLUSIONS. Isolating the global climate signature of anthropogenic aerosols and understanding the processes underlying regional trends in air quality depend upon separating small secular signals from natural variability. A long-term aerosol observing system that is capable of achieving these goals must combine observations from multiple vantage points using a variety of techniques. These elements must also work in conjunction with CTMs.
PARAGON adopts a systems approach to achieving an effective, balanced program. Relative to the current way of doing business, certain fundamental requirements need sustained attention. These include gaining greater support for achieving high instrumental calibration accuracies, developing new techniques for measuring and systematically validating key radiative and optical parameters, and supporting multiple observational approaches to ensure that climate inferences are robust. An invigorated, ongoing investment in improving the coverage, capabilities, and quality of data from surface-based networks is essential, coupled with a systematic program of aircraft in situ sampling. Technology advances can help to fill observational gaps and reduce indeterminacy in remote sensing retrievals. However, measurement idiosyncrasies and uncertainties must be well understood in order to separate changing satellite sensor characteristics from true Earth system variability. A systematic approach to satellite mission planning, taking into account how various sensors will operate in concert with other instruments and with models, needs to be put in place to ensure that resources are invested most effectively.

Careful attention to the basic capabilities outlined above is essential for building a firm foundation for global aerosol science; we anticipate no "silver bullet" that can do away with the need to develop and support them. An effort of this magnitude and complexity requires coordination among multiple national and international agencies, and a collaboration among researchers worldwide. PARAGON offers a unifying vision to help the scientific and policy-making communities reach this important goal.

ACKNOWLEDGMENTS. Support from the National Aeronautics and Space Administration, the National Oceanic and Atmospheric Administration, the National Science Foundation, and the U.S. Department of Energy is gratefully acknowledged. The research of D. J. Diner, R. A. Kahn, and R. T. Menzies was carried out at the Jet Propulsion Laboratory (JPL), California Institute of Technology, under contract with NASA. T. L. Anderson and R. J. Charlson acknowledge support from the National Science Foundation (Grant ATM-0138250). The research work of O. Torres is funded by NASA, and conducted at the Joint Center for Earth Systems Technology, University of Maryland Baltimore County. We thank J. Martonchik, B. Rheingans, C. Heeg, and A. Gerber of JPL for analyses in support of the orbit scenario discussion. We are grateful to R. M. Reynolds and G. Fargion of Brookhaven National Laboratory for providing helpful input regarding SOAR and SIMBIOS, D. Winker of NASA Langley Research Cen- 
ter for useful comments on the lidar sections, and L. Labonnote of the Laboratoire d'Optique Atmosphérique in Lille for the use of Fig. 3.

APPENDIX: PUTTING ORBIT SELECTION AND INSTRUMENT CAPABILITIES IN SYSTEM CONTEXT. Multiangle spectral and polarimetric imagers use radiances observed with nearsimultaneity in zenith angle and scattering angle as input to their retrieval algorithms. Although "high vista" orbits, such as a geostationary or L1 Lagrange point, are good choices for synoptic views and high temporal resolution [W. Wiscombe et al. 2002, personal communication (presentation online at http:// esto.nasa.gov/conferences/igarss-2002/02Presnt/ 02060940.ppt), hereafter WIS], they are not nearly as suitable as LEO or MEO orbits for this purpose. Geostationary earth orbit (GEO) satellites, for example, see each geographic region at a constant view angle; therefore, sensitivity to AOD depends on where the target is located relative to the subsatellite point. From L1, all points on the illuminated disk are observed in nearly direct backscatter. "Halo" orbits about the L1 point (WIS) can vary the earth-sun geometry, but with a lengthy orbit period of 6 months. Observing the same point at multiple view zenith angles must, therefore, make use of Earth rotation, but again the time scale is too long-an equatorial point rotates from a view angle of $60^{\circ}$ on one side of the subsatellite point to $60^{\circ}$ on the other side in about $8 \mathrm{~h}$.

From LEO or MEO, an along-track multiangle observing configuration, such as used by MISR, POLDER, and the Along-Track Scanning Radiometer (ATSR) series, provides the necessary observing geometry. For a future system, the relative merits of sunsynchronous (SS) versus precessing orbits, and the required coverage in latitude, need to be considered. Sun-synchronous orbits do not map diurnal variability, but they are valuable for minimizing diurnal effects that might otherwise complicate the data interpretation. We studied the required altitudes to achieve specified global coverage times as a function of the field of view (FOV) of an imager in SS orbit.

The altitude of an SS orbit is directly related to its inclination (Wehrle et al. 2002). For orbit altitudes $<3000 \mathrm{~km}$, the inclinations are within $22^{\circ}$ of polar. Coverage up to at least $80^{\circ}$ latitude is desirable for studying aspects of climate change, such as polar cloud cover. Two bounds on acceptable solutions are shown in Fig. A1: the minimum field angle (one-half of the FOV) required to achieve equator-to- $80^{\circ}$-latitude coverage, and the maximum field angle required to limit footprint growth across the swath. For the sake of argument, we chose a limit of $40 \%$ growth in pixel size. The maximum viewable latitude is a function of both the orbit inclination and the swath width. Figure A1 shows that a single satellite cannot satisfy the specified criteria and achieve global coverage in a single day. Another consideration is that the integrated radiation dose on instrument components is about 7 times higher for an SS orbit at $1500-\mathrm{km}$ altitude than at $800 \mathrm{~km}$, and increases by about another factor of 2 at $3000 \mathrm{~km}$. This affects the advisability of flying at altitudes required to obtain 2-day coverage. On the other hand, obtaining 3- or 4-day global coverage is attainable at lower orbit altitudes.

The benefits of combining a passive imager with a lidar are discussed in Ackerman et al. (2004) and references therein. An important step toward development of such a system is the satellite A train, in which Aqua (carrying a MODIS instrument), Aura [carrying the near-ultraviolet Ozone Monitoring Instrument (OMI); Torres et al. 2002b], a Myriade satellite carrying a POLDER derivative, and CALIPSO will fly in formation (M. R. Schoeberl 2002, personal communication). A program of routine aircraft underflights is needed to make systematic use of such data. Such deployments must account for the narrow lidar FOV. Spatiotemporal offsets need to be kept well within aerosol coherence scales, estimated at about $60 \mathrm{~km}$ and $3 \mathrm{~h}$ (Anderson et al. 2003a). Assuming a flight range of $200 \mathrm{~km}$, a dedicated aircraft based in the Tropics or midlatitudes would have 100 or more collocation opportunities per year for A-train underflights.

In the future, even more powerful constraints on aerosol microphysics and retrieval accuracies can be

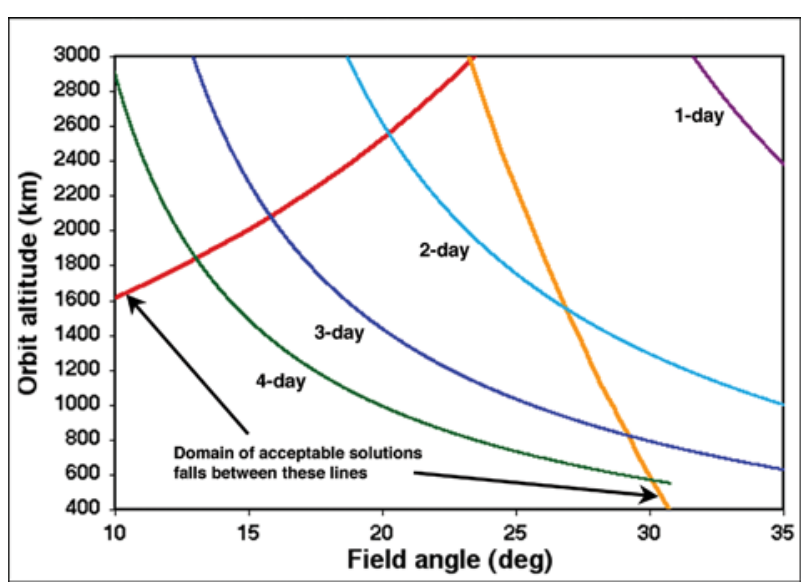

FIg. Al. Orbit altitudes as a function of the field angle of an imager (field angle = the half FOV) to achieve the specified global coverage times. Viable solutions fall between the red line (to achieve polar coverage) and the gold line (to limit footprint growth). 
obtained by combining an advanced, integrated imager with an advanced active system, such as HSRL. The following four potential mission scenarios illuminate some of the key mission design trade-offs:

- The simplest approach is to place the imager and lidar on the same platform at an orbit altitude that is a best compromise of their respective requirements. An example is the $640-\mathrm{km}$-altitude SS orbit with a ground-track repeat cycle of 15 days. From this altitude, the requirement to constrain pixel growth results in a global coverage time of 4 days. Perfect overlap between the imager and lidar is obtained (Fig. A2a).

- A second scenario places the imager in a MEO orbit providing 3-day global coverage, and puts the lidar on a separate satellite in LEO. For example, with an 1124-km SS orbit for the imager (17-day repeat cycle), a lidar at $392 \mathrm{~km}$ will complete exactly seven orbits for every six orbits of the imager. This commensurability in the orbit period results in the overlap coverage between the two instruments shown in Fig. A2b. If the lidar can point up to $\pm 45^{\circ}$ cross track, overlap with the imager's swath occurs between $83 \%$ and $100 \%$ of the time, depending on latitude. The time difference between when each overflies a given target varies between exact coincidence and $46 \mathrm{~min}$, well within the 3-h time scale for high correlation established by Anderson et al. (2003a).

- A third option places the imager in MEO and lidar in LEO, with both satellites in perfectly polar orbit (inclination $=90^{\circ}$ ). The descending node of the LEO satellite corresponds to the ascending node of the MEO satellite, that is, one satellite's orbit is prograde and the other is retrograde. The lidar is directly underneath the imager twice each orbit. Complete overlap with small overpass time differences is achieved, but exact polar orbit is required so that the orbit planes do not precess. This means that the orbits are not sun synchronous.

- A fourth possibility also uses two satellites, but both orbits are elliptical with identical semimajor axes, such that they have exactly the same period. By having the perigee of the lidar coincide with the apogee of the imager on the orbit dayside, nearperfect dayside spatial and temporal overlap is achieved. The main drawback of this approach is that the lines of apsides (the orbit semimajor axes) precess in latitude, so that within a few months the lidar perigee and the imager apogee will have migrated to the nightside. "Freezing" this precession of the line of apsides is possible by inclining both

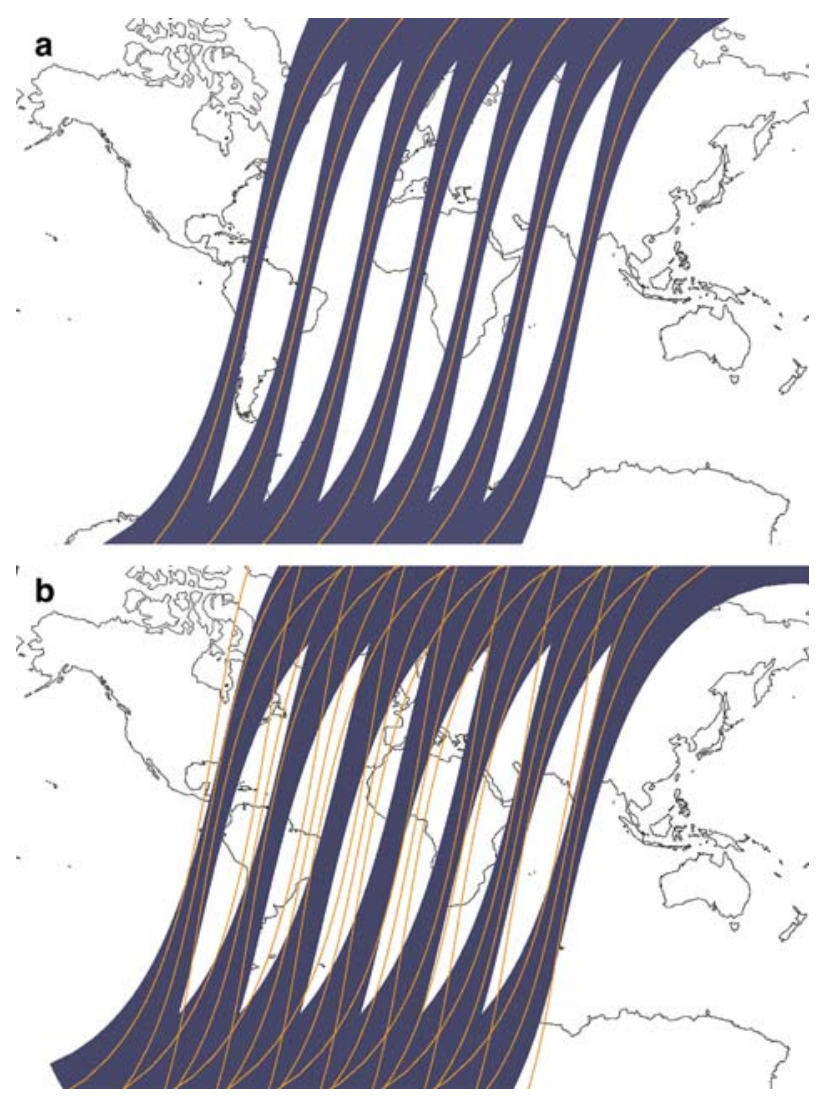

Fig. A2. (a) Overlap coverage for an imager and nonscanning lidar on the same spacecraft in LEO (640-km altitude). (b) Overlap coverage for an imager in MEO (I I 24-km altitude) and a scanning lidar in LEO (392-km altitude). The range to the surface in the off-nadir lidar views is $\mathbf{5 7 2} \mathbf{~ k m}$, so this scenario retains a roughly fourfold advantage in power requirements relative to placing the lidar at the same altitude as the imager. In both scenarios, seven consecutive imager orbits are shown.

orbits at $63.4^{\circ}$. However, at this inclination the orbits are not sun synchronous and polar coverage is sacrificed.

\section{REFERENCES}

Ackerman, T. P., and Coauthors, 2004: Integrating and interpreting aerosol observations and models within the PARAGON framework. Bull. Amer. Meteor. Soc., 85, 1523-1533.

Althausen, D., D. Muller, A. Ansmann, U. Wandinger, H. Hube, E. Clauder, and S. Zorner, 2000: Scanning 6-wavelength 11-channel aerosol lidar. J. Atmos. Oceanic Technol., 17, 1469-1482.

Anderson, T. L., R. J. Charlson, D. M. Winker, J. A. Ogren, and K. Holmen, 2003a: Mesoscale variations of tropospheric aerosols. J. Atmos. Sci., 60, 119-136. 
- S. J. Masonis, D. S. Covert, N. C. Ahlquist, S. G. Howell, A. D. Clarke, and C. S. McNaughton, 2003b: Variability of aerosol optical properties derived from in situ aircraft measurements during ACE-Asia. J. Geophys. Res., 108, 8647, doi:10.1029/2002JD003247.

Ansmann, A., M. Riebesell, and C. Weitkamp, 1990: Measurement of atmospheric aerosol extinction profiles with a Raman lidar. Opt. Lett., 15, 746-748.

Böckmann, C., and Coauthors, 2004: Aerosol lidar intercomparison in the framework of EARLINET: Part II-Aerosol backscatter algorithms. Appl. Opt., 43, 977-989.

Bond, T. C., T. L. Anderson, and D. Campbell, 1999: Calibration and intercomparison of filter-based measurements of visible light absorption by aerosols. Aerosol Sci. Technol., 30, 582-600.

Bösenberg, J., and Coauthors, 2002: EARLINET: Establishing the European Aerosol Research Lidar Network. Proc. 21st International Laser Radar Conf., Quebec City, QC, Canada, International Coordination-group for Laser Atmospheric Studies, 293296.

Brown, S. W., G. P. Eppeldauer, and K. R. Lykke, 2000: NIST facility for spectral irradiance and radiance responsivity calibrations with uniform sources. Metrologia, 37, 579-582.

Bruegge, C. J., W. A. Abdou, D. J. Diner, B. J. Gaitley, M. C. Helmlinger, R. A. Kahn, and J. V. Martonchik, 2004: Validation of the MISR radiometric scale for the ocean aerosol science communities. Proc. of the International Workshop on Radiometric and Geometric Calibration, Gulfport, MS, ISPRS and CEOS. [Available online at http://www.commission1.isprs.org/ isprs_ceos_workshop/.]

Bruneau, D., and J. Pelon, 2003: Simultaneous measurements of particle backscattering and extinction coefficients and wind velocity by lidar with a MachZehnder interferometer: Principle of operation and performance assessment. Appl. Opt., 42, 1101-1114.

Cairns, B., L. D. Travis, and E. E. Russell, 1999: The Research Scanning Polarimeter: Calibration and groundbased measurements. Proc. SPIE, 3754, 186-196.

Cattrall, C., K. L. Carder, and H. R. Gordon, 2003: Columnar aerosol single-scattering albedo and phase function retrieved from sky radiance over the ocean: Measurements of Saharan dust. J. Geophys. Res., 108, 4287, doi:10.1029/2002JD002497.

Chin, M., and Coauthors, 2002: Tropospheric aerosol optical thickness from the GOCART model and comparisons with satellite and sunphotometer measurements. J. Atmos. Sci., 59, 461-482.

Chowdhary, J., B. Cairns, and L. D. Travis, 2002: Case studies of aerosol retrievals over the ocean from multiangle, multispectral photopolarimetric remote sensing data. J. Atmos. Sci., 59, 383-397.

Delene, D. J., and J. A. Ogren, 2002: Variability of aerosol optical properties at four North American surface monitoring sites. J. Atmos. Sci., 59, 1135-1150.

Diner, D. J., and Coauthors, 2004a: PARAGON: An integrated approach for characterizing aerosol climate impacts and environmental interactions. Bull. Amer. Meteor. Soc., 85, 1491-1501.

— , R. A. Chipman, B. Cairns, L. D. Foo, C. Keller, S. A. Macenka, and C. F. Bruce, 2004b: High-accuracy multiangle spectropolarimetric imaging concept for aerosol remote sensing from space. Eos Trans. Amer. Geophys. Union, 85, (Joint Assembly Suppl.), GC21A-07.

Dubovik, O., C. Gatebe, A. Sinyuk, E. Vermote, M. King, and B. Holben, 2003: Aerosol and surface retrieval from a combination of up-looking and down-looking observations. IGARSS Meeting 2003, Toulouse, France, IGARSS. [Available online at http:// car.gsfc.nasa.gov/_ppt/IGARSS_2003.ppt.]

Eppeldauer, G. P., S. W. Brown, T. C. Larson, M. Rácz, and K. R. Lykke, 2000: Realization of a spectral radiance responsivity scale with a laser-based source and Si radiance meters. Metrologia, 37, 531-534.

Fargion, G. S., R. Barnes, and C. McClain, 2001: In situ aerosol optical thickness collected by the SIMBIOS program (1997-2000): Protocols, and data QC and analysis. NASA Tech. Memo. 209982, 103 pp.

Gandorfer, A. M., and H. P. Povel, 1997: First observations with a new imaging polarimeter. Astron. Astrophys., 328, 381-389.

GCOS, 2003: The second report on the adequacy of the global observing systems for climate in support of the UNFCCC. WMO Tech. Rep. WMO/TD 1143, 85 pp. Hagolle, O., and Coauthors, 1999: Results of POLDER in-flight calibration. IEEE Trans. Geosci. Remote Sens., 37, 1550-1566.

Hair, J. W., L. M. Caldwell, D. A. Krueger, and C. Y. She, 2001: High-spectral-resolution lidar with iodine-vapor filters: Measurement of atmospheric-state and aerosol profiles. Appl. Opt., 40, 5280-5294.

Holben, B. N., and Coauthors, 1998: AERONET_-A federated instrument network and data archive for aerosol characterization. Remote Sens. Environ., 66, 1-16. —-, and Coauthors, 2001: An emerging ground based aerosol climatology: Aerosol optical depth from AERONET. J. Geophys. Res., 106, 12 067-12 097.

Kahn, R., and Coauthors, 2004a: Environmental snapshots from ACE-Asia. J. Geophys. Res., in press.

— their roles within PARAGON. Bull. Amer. Meteor. Soc., 85, 1511-1522. 
— , and Coauthors, 2004c: MISR calibration, and implications for low-light-level aerosol retrieval over dark water. J. Atmos. Sci., in press.

Kaufman, Y. J., J. V. Martins, L. A. Remer, M. R. Schoeberl, and M. A. Yamasoe, 2002a: Satellite retrieval of aerosol absorption over the oceans using sunglint. Geophys. Res. Lett., 29, 1928, doi:10.1029/ 2002 GL015403.

— - D. Tanré, and O. Boucher, 2002b: A satellite view of aerosols in the climate system. Nature, 419, 215223.

Keller, C. U., 2002: Instrumentation for astrophysical spectropolarimetry. Astrophysical Spectropolarimetry, J. Trujillo-Bueno, F. Moreno-Insertis, and F. Sanchez, Eds., Cambridge University Press, 303354.

- 2003: Charge-Caching CMOS Detector for Polarimetry (C3Po). Proc. SPIE, 5171, 239-246.

Klett, J. D., 1981: Stable analytic inversion solution for processing LIDAR returns. Appl. Opt., 20, 211-220.

—, 1985: LIDAR inversion with variable backscatter/ extinction ratios. Appl. Opt., 24, 1638-1643.

Labonnote, L. C., and G. L. Stephens, 2003: Capability of high resolution A-band measurements to infer the aerosol single scattering albedo. Geophys. Res. Abstr., 5,12526 .

Matthias, V., and Coauthors, 2003: Aerosol lidar intercomparison in the framework of EARLINET: Part I-Instruments. Appl. Opt., 43, 961-976.

Miller, M. A., M. J. Bartholomew, and R. M. Reynolds, 2004: The accuracy of marine shadow-band sun photometer measurements of aerosol optical thickness and Ångström exponent. J. Atmos. Oceanic Technol., 21, 397-410.

Mishchenko, M. I., and L. D. Travis, 1997: Satellite retrieval of aerosol properties over the ocean using polarization as well as intensity of reflected sunlight. $J$. Geophys. Res., 102, 16 989-17 014.

— - A. A. Lacis, B. E. Carlson, and L. D. Travis, 1995: Nonsphericity of dust-like tropospheric aerosols: Implications for aerosol remote sensing and climate modeling. Geophys. Res. Lett., 22, 1077-1080.

Moroney, C., R. Davies, and J.-P. Muller, 2002: Operational retrieval of cloud-top heights using MISR data. IEEE Trans. Geosci. Remote Sens., 40, 15-41.

Müller, D., U. Wandinger, and A. Ansmann, 1999a: Microphysical particle parameters from extinction and backscatter lidar data by inversion with regularization: Theory. Appl. Opt., 38, 2346-2357.

— — , and — 1999b: Microphysical particle parameters from extinction and backscatter lidar data by inversion with regularization: Simulation. Appl. Opt., 38, 2358-2368.
, F. Wagner, U. Wandinger, A. Ansmann, M. Wendisch, D. Althausen, and W. von HoyningenHuene, 2000a: Microphysical particle parameters from extinction and backscatter lidar data by inversion with regularization: Experiment. Appl. Opt., 39, 1879-1892.

—, - D. Althausen, U. Wandinger, and A. Ansmann, 2000b: Physical particle properties of the Indian aerosol plume derived from six-wavelength lidar observations on 25 March 1999 of the Indian Ocean Experiment. Geophys. Res. Lett., 27, 1403-1406.

—, U. Wandinger, D. Althausen, and M. Fiebig, 2001: Comprehensive particle characterization from threewavelength Raman-lidar observations: Case study. Appl. Opt., 40, 4863-4869.

Muller, J.-P., A. Mandanayake, C. Moroney, R. Davies, D. J. Diner, and S. Paradise, 2002: MISR stereoscopic image matchers: Techniques and results. IEEE Trans. Geosci. Remote Sens., 40, 1547-1559.

NACIP, 2002: What systematic observations are needed to reduce uncertainty in direct and indirect forcing? NACIP Working Group 4 Rep., 3 pp. [Available online at http://www.nacip.ucsd.edu/ N A C I P meetings / N A CIPJ an $2002 \mathrm{mtg} /$ N A C I Pworking groupReports Jan $02 /$ NACIPwg4RapportRepJan2902.pdf.]

Naud, C., J.-P. Muller, M. Haeffelin, Y. Morille, and A. Delaval, 2004: Assessment of MISR and MODIS cloud top heights through inter-comparison with a back-scattering lidar at SIRTA. Geophys. Res. Lett., 31, L04114, doi:10.1029/2003GL018976.

NRC, 1999: Adequacy of Climate Observing Systems. National Academy Press, 51 pp.

O’Brien, D. M., R. M. Mitchell, S. A. English, and G. A. Da Costa, 1998: Airborne measurements of air mass from $\mathrm{O}_{2}$ A-band absorption spectra. J. Atmos. Oceanic Technol., 15, 1271-1286.

Ohring, G., B. Wielicki, R. Spencer, W. Emery, and R. Datla, Eds., 2004: Satellite instrument calibration for measuring global climate change. National Institute of Standards and Technology Rep. 7047, 114 pp. [Available online at http://physics.nist.gov/Divisions/Div844/publications/NISTIR7047/ nistir7047.pdf.]

Penner, J. E., and Coauthors, 2001: Aerosols, their direct and indirect effects. Climate Change 2001: The Scientific Basis, J. T. Houghton et al., Eds., Cambridge University Press, 289-416.

Poole, L. R., D. M. Winker, J. R. Pelon, and M. P. McCormick, 2003: CALIPSO: Global aerosol and cloud observations from lidar and passive instruments. Proc. SPIE, 4881, 419-426.

Povel, H., C. U. Keller, and I.-A. Yadigaroglu, 1994: Twodimensional polarimeter with a charge-coupled-de- 
vice image sensor and a piezoelastic modulator. Appl. Opt., 33, 4254-4260.

Ramanathan, V., and Coauthors, 2001: Indian Ocean Experiment: An integrated analysis of the climate forcing and effects of the great Indo-Asian haze. $J$. Geophys. Res., 106, 28 371-28 398.

Rasch, P. J., W. D. Collins, and B. E. Eaton, 2001: Understanding the Indian Ocean Experiment (INDOEX) aerosol distributions with an aerosol assimilation. J. Geophys. Res., 106, 7337-7345.

Reynolds, R. M., M. A. Miller, and M. J. Bartholomew, 2001: Design, operation, and calibration of a shipboard fast-rotating shadowband radiometer. $J$. Atmos. Oceanic Technol., 18, 200-214.

Russell, P. B., and Coauthors, 2002: Comparison of aerosol single scattering albedos derived by diverse techniques in two North Atlantic experiments. J. Atmos. Sci., 59, 609-619.

Seinfeld, J. H., and Coauthors, 2004: Scientific objectives, measurement needs, and challenges motivating the PARAGON aerosol initiative. Bull. Amer. Meteor. Soc., 85, 1503-1509.

She, C. Y., R. J. Alvarez II, L. M. Caldwell, and D. A. Krueger, 1992: High-spectral-resolution RayleighMie lidar measurement of aerosol and atmospheric profiles. Opt. Lett., 17, 541-543.

Shipley, S. T., D. H. Tracy, E. W. Eloranta, J. T. Trauger, J. T. Sroga, F. L. Roesler, and J. A. Weinman, 1983: High spectral resolution lidar to measure optical scattering properties of atmospheric aerosols. 1: Theory and instrumentation. Appl. Opt., 22, 3716-3723.

Sroga, J. T., E. W. Eloranta, S. T. Shipley, F. L. Roesler, and J. A. Weinman, 1983: High spectral resolution lidar to measure optical scattering properties of atmospheric aerosols. 2: Calibration and data analysis. Appl. Opt., 22, 3725-3730.

Stephens, G. L., and A. Heidinger, 2000: Molecular line absorption in a scattering atmosphere. Part I: Theory. J. Atmos. Sci., 57, 1599-1614.

Torres, O., P. K. Bhartia, J. R. Herman, and Z. Ahmad, 1998: Derivation of aerosol properties from satellite measurements of backscattered ultraviolet radiation. Theoretical basis. J. Geophys. Res., 103, 17 099-17 110.

,,$-- \ldots$, A. Syniuk, P. Ginoux, and B. Holben, 2002a: A long-term record of aerosol optical depth from TOMS observations and comparison to AERONET measurements. J. Atmos. Sci., 59, 398413.

—, R. Decae, and P. Veefkind, 2002b: OMI Aerosol Retrieval Algorithm. Vol. 3, OMI Algorithms Theoretical Basis Document: Clouds, Aerosols and Surface UV Irradiance, P. Stammes, Ed., NASA-KNMI Tech. Doc. ATBD-OMI-03, 114 pp.

Veselovskii, I., A. Kolgotin, V. Griaznov, D. Muller, U. Wandinger, and D. N. Whiteman, 2002: Inversion with regularization for the retrieval of tropospheric aerosol parameters from multiwavelength lidar sounding. Appl. Opt., 41, 3685-3700.

Wang, M., and H. R. Gordon, 1993: Retrieval of the columnar aerosol phase function and single-scattering albedo from sky radiance over the ocean: Simulations. Appl. Opt., 32, 4598-4609.

$\longrightarrow$, and ——, 1994: Estimating aerosol optical properties over the oceans with MISR: Some preliminary studies. Appl. Opt., 33, 4042-4057.

Wehrle, V. A., H. C. Webster, and A. A. Fratpietro, 2002: A systematic methodology for selecting the scienceoptimized orbit for the Atmospheric Chemistry Experiment mission. Can. Aeronaut. Space J., 48, 25-29.

Welton, E. J., J. R. Campbell, J. D. Spinhirne, and V. S. Scott, 2001: Global monitoring of clouds and aerosols using a network of micro-pulse lidar systems. Proc. SPIE, 4153, 151-158.

Winker, D., J. Pelon, and M. P. McCormick, 2002: The CALIPSO mission: Aerosol and cloud observations from space. Proc. 21st Int. Lidar Radar Conf., Quebec City, QC, Canada, International Coordinationgroup for Laser Atmospheric Studies, 735-738.

Yu, H., R. E. Dickinson, M. Chin, Y. J. Kaufman, B. N. Holben, I. V. Geogdzhayev, and M. I. Mishchenko, 2003: Annual cycle of global distributions of aerosol optical depth from integration of MODIS retrievals and GOCART model simulations. J. Geophys. Res., 108, 4128, doi:10.1029/2002JD002717.

Zong, J., R. Davies, J.-P. Muller, and D. J. Diner, 2002: Photogrammetric retrieval of cloud advection and top height from the Multi-angle Imaging SpectroRadiometer (MISR). Photogramm. Eng. Remote Sens., 68, 821-829. 